- vielleicht 100 bis 180 Grm. wiegenden - Bleikönig in einen ziemlich geräumigen hessischen Tiegel in der Rothglühhitze in guten Fluss, fügt eine Kalisalpetermenge hinzu, welche etwa halb so viel wiegt als das Blei, steigert die Hitze, bis der Tiegel bis zum Rande weiss glühend ist, rührt dessen Inhalt mit einem spitzen Eisenstabe um, nimmt ihn aus dem Feuer - bevor er vom Bleioxyd durchgefressen ist - lässt ihn erkalten und zerschlägt ihn. Nöthigenfalls muss diese Verschlackung zwei- oder dreimal wiederholt werden. Die einzige zu beachtende Vorsicht besteht in der Sorgfalt für Hervorbringung einer vollon Weissgluth und zeitige Entfernung des Tiegels aus dem Feuer, bevor er Schaden leidet. - Dieses Verfahren lässt sich selbstverständlicher Weise noch einen Schritt weiter treiben, so dass man zuletzt einen reinen Goldkönig erhält, und in der That soll nach dem Verfasser die Goldprobe in letzterer Weise ohne alle Kupellation hin und wieder im Gebrauche sein.

T. M. Blossom*) macht übrigens, wohl mit Recht, darauf aufmerksam, dass Bleikönige von 100 bis $180 \mathrm{Grm}$. bei gut ausgeführten Proben kaum erhalten werden dürften und dass die Behandlung in der Muffel nach dem gewöhnlichen Verfahren rascher zum Ziele führen möchte als Merrick's Methode.

\title{
Zur Nachweisung kleiner Mengen Schwefels im Leuchtgase
} streicht V. W arth $a^{* *}$ ) mit einer an einem feinen Platindrahte befestigten Perle von Soda an den Rändern der Flamme her und senkt dieselbe sodann in die leuchtende Flamme, wodurch das vorher gebildete schwefelsaure und schwefligsaure Natron zu Schwefelnatrium reducirt werden. Wird nun die Perle anf einem Porcellanteller zerdrückt und eine Lösung von Nitroprussidnatrium darauf getröpfelt, so gibt sich die kleinste Spur Schwefel zu erkennen. Die Reaction soll $50 \mathrm{mal}$ so empfindlich sein als die auf Silberblech. Für Leuchtgas genügen 1 bis 2 Minuten, während V ogel für seine Schwefelkupfer-Reaction 4 Stunden Zeit nöthig hat.

Zur Erkennung und Unterscheidung der fetten oele benutzt. Massie ${ }^{* * *}$ ) die Farbenveränderungen, welche dieselben unter dem gleichzeitigen Einfluss von Salpetersäure und metallischem Quecksilber erleiden. Der Verfasser hat die Resultate seiner Versuche in einer zahlreiche

*) American Chemist Bd. 1, p. 380.

**) Ber. d. dentsch. chem. Gesellsch. Bd. 4, p. 529.

***) Journ. de pharm. et de chim. [IV] Bd. 12, p. 13. 